\title{
Dough Rheology and Baked Product Texture
}




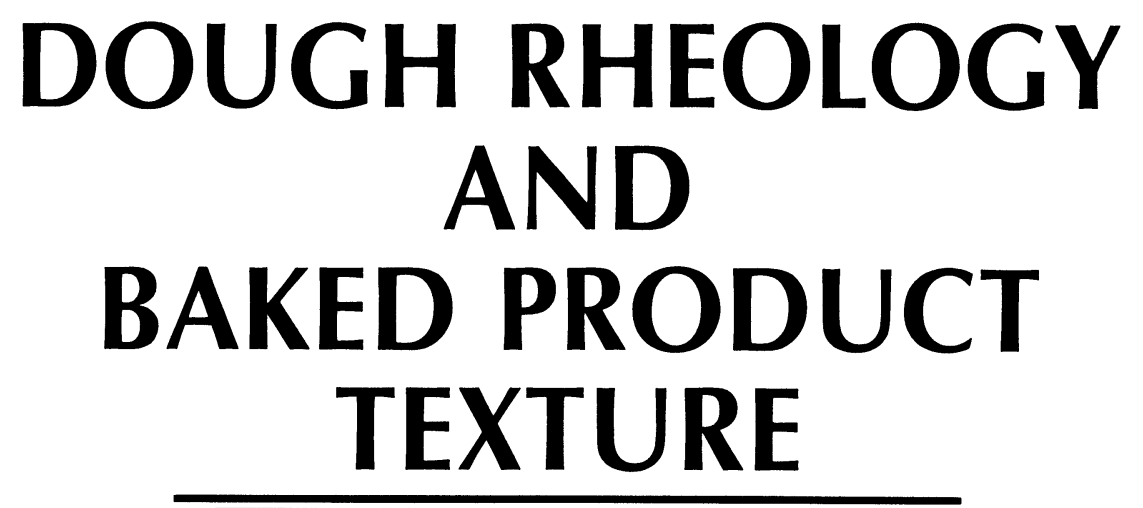

Edited by

Hamed Faridi, Ph.D.

Nabisco Brands, Incorporated

East Hanover, New Jersey

\section{Jon M. Faubion, Ph.D. \\ Kansas State University \\ Manhattan, Kansas}

\section{An avi Book}

Published by Van Nostrand Reinhold

New York 


\author{
An AVI Book \\ (AVI is an imprint of Van Nostrand Reinhold) \\ Copyright (c) 1990 by Van Nostrand Reinhold \\ Softcover reprint of the hardcover 1st edition 1990 \\ Library of Congress Catalog Card Number 89-5594 \\ ISBN-13:978-1-4612-8207-5 \\ e-ISBN-13:978-1-4613-0861-4 \\ DOI:10.1007/978-1-4613-0861-4
}

All rights reserved. No part of this work covered by the copyright hereon may be reproduced or used in any form by any means-graphic, electronic, or mechanical, including photocopying, recording, taping, or information storage and retrieval systems - without written permission of the publisher.

Van Nostrand Reinhold

115 Fifth Avenue

New York, New York 10003

Van Nostrand Reinhold International Company Limited

11 New Fetter Lane

London EC4P 4EE, England

Van Nostrand Reinhold

480 La Trobe Street

Melbourne, Victoria 3000, Australia

Nelson Canada

1120 Birchmount Road

Scarborough, Ontario M1K 5G4, Canada

$\begin{array}{llllllllllllllll}16 & 15 & 14 & 13 & 12 & 11 & 10 & 9 & 8 & 7 & 6 & 5 & 4 & 3 & 2 & 1\end{array}$

\title{
Library of Congress Cataloging-in-Publication Data
}

Dough rheology and baked product texture/edited by Hamed A. Faridi and Jon M. Faubion.

p. $\mathrm{cm}$.

Bibliography: $p$.

1. Dough-Mechanical properties. 2. Baked products-Texture.

I. Faridi, Hamed. II. Faubion, Jon M.

TX560.D68D68 1989

$664^{\prime} .752-\mathrm{dc} 19$ 


\section{Contents}

Foreword vii

Preface ix

Contributors $x i$

1. Fundamental Aspects of Dough Rheology

J. A. Menjivar

2. The Viscoelastic Properties of Wheat Flour Doughs

J. M. Faubion and R. C. Hoseney

3. Rheological Properties of Cereal Proteins

A.-C. Eliasson

4. Rheological Properties of Cereal Carbohydrates J.-L. Doublier

5. Influences of the Glassy and Rubbery States on the Thermal, Mechanical, and Structural Properties of Doughs and Baked Products

$H$. Levine and L. Slade

6. Basic Principles of Food Texture Measurement

M. C. Bourne

7. Application of Rheology in the Bread Industry $R$. Spies

8. Application of Rheology in the Cookie and Cracker Industry

H. Faridi

9. Application of Rheology in the Pasta Industry D. H. Hahn

10. Application of Rheology in the Breakfast Cereal Industry 405 J. Loh and W. Mannell 
11. Influence of Extrusion Processing on In-Line Rheological Behavior, Structure, and Function of Wheat Starch

B. van Lengerich

12. Rheology in Process Engineering $R$. Leschke

13. Interrelationships of Rheology, Kinetics, and Transport Phenomena in Food Processing R. Y. Ofoli

14. Rheological and Engineering Aspects of the Sheeting and Laminating of Doughs

L. Levine and B. A. Drew

15. Practical Texture Measurements of Cereal Foods M. C. Bourne

16. Texture Evaluation of Baked Products Using Descriptive Sensory Analysis

L. M. Hansen and C. S. Setser

Index 597 


\section{Foreword}

Cereal chemists are interested in rheology because the dough undergoes some type of deformation in every phase of the conversion of flour into baked products. During mixing, dough is subjected to extreme deformations, many that exceed the rupture limit; during fermentation, the deformations are much smaller and therefore exhibit a different set of rheological properties; during sheeting and molding, deformations are at an intermediate level; and, finally, during proofing and baking, the dough is subjected to a range of deformations at varying temperatures. Accordingly, the application of rheological concepts to explain the behavior of dough seems a natural requirement of research on the interrelationships among flour constituents, added ingredients, process parameters, and the required characteristics of the final baked product. At any moment in the baking process, the rheological behavior, that is, the nature of the deformation, exhibited by a specific dough derives from the applied stress and how long the stress is maintained. The resulting deformation may be simple, such as pure viscous flow or elastic deformation, and therefore easy to define precisely. Moreover, under some conditions of stress and time (i.e., shear rate), doughs behave as ideal materials and their behavior follows theory derived from fundamental concepts. Under usual conditions encountered in baking, however, the rheological behavior is far from ideal; shear rates vary widely and sample size and dimensions are ill-defined. Because of the highly variable and complex conditions of deformation and sample dimensions, a wide gap persists between technologically practiced and theoretical rheology as applied to bread doughs.

Significant progress has been made in the development of theory and appropriate instrumentation for research on the fundamental aspects of dough rheology; this progress is the subject of the first six chapters of Dough Rheology and Baked Product Texture. New fundamental equations have been developed, and instruments have been perfected to measure the necessary parameters. Computers have become an integral part of the instruments and are used for data processing; the ability to process the results rapidly facilitates on-line measurements. The remaining chapters deal with aspects of rheology applied to the processing of cereals into specific consumer products.

Developments in applied dough rheology have followed innovations in instrumentation. Because the common approach to instrument development has been to imitate the breadmaking process, the instruments are highly empirical. Many of the empirical instruments have been very useful in practical quality control, but they have had limited value in generating fundamental data. On the other hand, instruments that lead to the determination of fundamental parameters have not found general use in the mill or bakery laboratories. Accordingly, research is needed to fill the gap between theory and practice. 
In reviewing the history of applied dough rheology, one cannot help but be impressed by the breadth of the contributions of one person, Carl Wilhelm Brabender (1897-1970). He has left a legacy of a series of high-quality instruments designed to measure physical properties of doughs at all stages of the baking process. His contributions to cereal chemistry go far beyond the development of instruments. His three-phase concept of breadmaking, formulated in the 1950s and published in Cereal Foods World (1965), has withstood the test of time. For each of the three phases - mixing, fermentation and machining, and baking - he developed an instrument to measure the rheological properties of the dough: the farinograph for the mixing phase, the extensograph for the fermentation and machining phase, and the amylograph for the baking phase. Brabender postulated that if two or more flours gave the same results by the three instruments, they would give the same result by the baking test. Accordingly, it became possible to define flours in terms of quantitive parameters determined with each instrument. This approach has become common practice in many countries.

Furthermore, Brabender showed that deviations from specifications can readily be corrected by changing the wheat mix to adjust the farinogram, by adding oxidizing improvers to adjust the extensigram, and by adding diastatic malt or changing the wheat mix to adjust the amylogram. Subsequent modifications in the farinograph with the development of the high-shear model and the Do-Corder made it a useful instrument in the modern mechanical development of breadmaking processes. The extensograph and the amylograph have remained virtually unchanged for over 50 years.

So far, the complexity of the dough system and the variability of the baking process have prevented the rheologists from developing a rigorous equation of state based on composition, deformation, time, and temperature. This is the challenge for future dough rheologists. 


\section{Preface}

This book contains 16 chapters of concise and up-to-date review of various aspects of dough rheology and baked product texture. It is the most comprehensive review ever published on the subject and we hope that it will be used worldwide as a reference by researchers, baking technologists, food scientists, engineers, quality control staff of bakeries, students, and others working in the baked product manufacturing industries.

Since the 1950s, the production plants of the large bakers have become bigger, more automated, and, most importantly, less tolerant of variations in the functionality of ingredients and of changes in processing conditions. Variabilities that could have been absorbed easily 30 years ago today cause serious manufacturing problems that affect both product quality and operating profits. This volume is intended to fill a technical gap that exists in our industry. We hope that it will help the baking industry to appreciate the science of dough rheology and to apply the know-how needed to minimize day-to-day manufacturing problems.

Our sincere thanks to the distinguished experts from industry and academia who contributed manuscripts to this volume. Our thanks are also extended to the editorial staff of Van Nostrand Reinhold, Inc., and Beehive Production Services for their excellent suggestions and editing of the text. 


\section{Contributors}

Malcolm C. Bourne, Institute of Food Science and Technology, Cornell University, Geneva, New York 14456

Jean-Louis Doublier, Laboratoire de Physicochemie des Macromolecules, Institut National de las Recherche Agronomique, B.P. 27, Nantes, Cedex 03, France

Bruce A. Drew, 4425 Abbott Avenue South, Minneapolis, Minnesota 55410

Ann-Charlotte Eliasson, Department of Food Technology, University of Lund, Box 124, S-221 00 Lund, Sweden

Hamed Faridi, RMS Technology Center, Nabisco Brands Incorporated, 200 Deforest Avenue, P.O. Box 1943, East Hanover, New Jersey 07936

Jon M. Faubion, Department of Grain Science and Industry, Shellenberger Hall, Kansas State University, Manhattan, Kansas 66506

David H. Hahn, Hershey Foods Corporation, Hershey, Pennsylvania 17033

Laura M. Hansen, Department of Foods and Nutrition, Kansas State University, Manhattan, Kansas 66506

R. Carl Hoseney, Department of Grain Science and Industry, Shellenberger Hall, Kansas State University, Manhattan, Kansas 66506

Rudolph Leschke, 5550 Via Vallarta, Yorba Linda, California 92686

Harry Levine, Fundamental Science Group, Nabisco Brands Incorporated, P.O. Box 1943, East Hanover, New Jersey 07936

Leon Levine, Levine \& Associates Incorporated, 2665 Jewel Lane, Plymouth, Minnesota 55447

Jimbay Loh, General Foods Corporation, 555 South Broadway, Tarrytown, New York 10591

Wesley Mannell, General Foods Corporation, 555 South Broadway, Tarrytown, New York 10591 


\section{xii / Contributors}

Juan A. Menjivar, RMS Technology Center, Nabisco Brands Incorporated, 200 Deforest Avenue, P.O. Box 1943, East Hanover, New Jersey 07936

Robert Y. Ofoli, Department of Agricultural Engineering, 102 Farrall Hall, Michigan State University, East Lansing, Michigan 48824

Carole S. Setser, Department of Foods and Nutrition, Kansas State University, Manhattan, Kansas 66506

Louise Slade, Fundamental Science Group, Nabisco Brands Incorporated, P.O. Box 1943, East Hanover, New Jersey 07936

Ronald Spies, Continental Baking Company, 1 Checkerboard Square, St. Louis, Missouri 63164

Bernhard van Lengerich, Fairlawn Development Center, Nabisco Brands Incorporated, Fairlawn, New Jersey 07410 